\title{
Breast reconstruction after mastectomy at a comprehensive cancer center
}

\author{
Shahnjayla K. Connors ${ }^{1 *}$, Melody S. Goodman ${ }^{1}$, Terence Myckatyn², Julie Margenthaler ${ }^{3}$ and Sarah Gehlert ${ }^{1,4}$
}

\begin{abstract}
Background: Breast reconstruction after mastectomy is an integral part of breast cancer treatment that positively impacts quality of life in breast cancer survivors. Although breast reconstruction rates have increased over time, African American women remain less likely to receive breast reconstruction compared to Caucasian women. National Cancer Institute-designated Comprehensive Cancer Centers, specialized institutions with more standardized models of cancer treatment, report higher breast reconstruction rates than primary healthcare facilities. Whether breast reconstruction disparities are reduced for women treated at comprehensive cancer centers is unclear. The purpose of this study was to further investigate breast reconstruction rates and determinants at a comprehensive cancer center in St. Louis, Missouri.

Methods: Sociodemographic and clinical data were obtained for women who received mastectomy for definitive surgical treatment for breast cancer between 2000 and 2012. Logistic regression was used to identify factors associated with the receipt of breast reconstruction.

Results: We found a breast reconstruction rate of $54 \%$ for the study sample. Women who were aged 55 and older, had public insurance, received unilateral mastectomy, and received adjuvant radiation therapy were significantly less likely to receive breast reconstruction. African American women were $30 \%$ less likely to receive breast reconstruction than Caucasian women.

Conclusion: These findings suggest that racial disparities in breast reconstruction persist in comprehensive cancer centers. Future research should further delineate the determinants of breast reconstruction disparities across various types of healthcare institutions. Only then can we develop interventions to ensure all eligible women have access to breast reconstruction and the improved quality of life it affords breast cancer survivors.
\end{abstract}

Keywords: Breast reconstruction, Mastectomy, Breast cancer, Comprehensive cancer center, Disparities

\section{Background}

Breast reconstruction after mastectomy has become an important component of the breast cancer care continuum for patients who receive mastectomy (Alderman et al. 2009; Jagsi et al. 2014; Tseng et al. 2010), in part because of its positive effects on psychosocial functioning and quality of life. Breast cancer patients who undergo reconstruction experience less distress, better body image, better sexual function, and higher selfesteem than those who do not undergo reconstruction

\footnotetext{
*Correspondence: connorss@wudosis.wustl.edu

${ }^{1}$ Division of Public Health Sciences, Department of Surgery, Washington

University in St. Louis School of Medicine, St. Louis, MO, USA

Full list of author information is available at the end of the article
}

(Al-Ghazal et al. 2000; Atisha et al. 2008; Harcourt et al. 2003; Rowland et al. 1993; Wilkins et al. 2000). These women also report better physical functioning and less pain (Eltahir et al. 2013). Thus, the long-term benefits that breast reconstruction affords, suggests that equitable access to this procedure optimizes breast cancer survivorship (Alderman et al. 2009).

Although breast reconstruction rates have increased over time, they remain relatively low, ranging from 5 to $42 \%$ in population-based and institution-based studies (Brennan and Spillane 2013; Platt et al. 2011; Wilkins and Alderman 2004). These studies have found that reconstruction rates are significantly lower in African American compared to Caucasian women (Alderman 
et al. 2009, 2011; Butler et al. 2015; Greenberg et al. 2008; Hershman et al. 2012; Katz et al. 2005; Merchant et al. 2015; Morrow et al. 2005; Reuben et al. 2009; Rosson et al. 2008; Rowland et al. 2000; Tseng et al. 2004; Yang et al. 2013a, b), a disparity that has been attributed to racial differences in access to breast reconstructive services (Agarwal et al. 2011; Enewold et al. 2014; Greenberg et al. 2008; Katz et al. 2005; Offodile et al. 2015; Rowland et al. 1993; Wexelman et al. 2014) secondary to lower socioeconomic status (Alderman et al. 2003; Greenberg et al. 2008; Joslyn 2005; Katz et al. 2005; Kruper et al. 2011a; Offodile et al. 2015; Wexelman et al. 2014) and no or inadequate insurance (Alderman et al. 2006; Bradley et al. 2012; Enewold et al. 2014; Wexelman et al. 2014).

National Cancer Institute-designated Comprehensive Cancer Centers (NCI-CCCs) are tertiary, specialized cancer centers that have higher breast reconstruction rates than those reported by primary healthcare institutions and population-based reports (Brennan and Spillane 2013). This may be because of the more standardized infrastructures imposed by NCI oversight, increased financial resources, higher numbers of reconstructive surgeons focused on breast cancer care, or because surgeons at these institutions are somehow more aware of the psychological impact of breast reconstruction (Greenberg et al. 2011; Reuben et al. 2009). The latter may be due to the cross-disciplinary nature of NCI-CCCs.

It is unclear whether racial disparities in breast reconstruction are reduced in women treated for breast cancer at NCI-CCCs compared to other healthcare institutions, which one would expect if access to care was the sole or most salient issue. Yet, few studies have focused on determinants of breast reconstruction within NCI-CCCs (Christian et al. 2006; Elmore et al. 2012; Greenberg et al. 2011; Sharma et al. 2015; Tseng et al. 2004). It is important to examine breast reconstruction in different types of healthcare institutions to gain a better understanding of the determinants across health care settings (Iskandar et al. 2015). Understanding characteristics that are associated with the receipt of high quality breast cancer care, such as that reported for NCI-CCCs, are essential for identifying and implementing the best practices needed to ensure equitable access to breast reconstruction for all women (Onega et al. 2014). Previous studies at Siteman Cancer Center focused on specific patient groups and utilized smaller sample sizes (Connors et al. 2014; Elmore et al. 2012; Sharma et al. 2015). The purpose of this study was to utilize a large multi-year sample to conduct a comprehensive examination of the rate and determinants of breast reconstruction at Siteman Cancer Center, a NCICCC located in Saint Louis, Missouri.

\section{Methods}

\section{Data source}

Siteman Cancer Center is affiliated with the Washington University in St. Louis School of Medicine and BJC HealthCare of St. Louis, a 12-hospital system. We obtained de-identified data for women who received mastectomy for definitive surgical treatment for breast cancer at Siteman Cancer Center between 2000 and 2012. Data were obtained from the Barnes-Jewish Hospital (BJH) Cancer Registry that is maintained by Oncology Data Services (ODS). The Human Research Protection Office (HRPO) and Institutional Review Board (IRB) at Washington University in St. Louis gave this study exempt status.

Data were obtained for 5421 women. The percentage of women of Asian descent was small $(n=120)$, therefore, we excluded these women from analysis. We also excluded 1147 women who received partial or segmental mastectomies, which are often lumpectomies that rarely receive breast reconstruction. The 1147 women excluded accounted for $1 \%$ of the reconstruction in the original sample. The final sample consisted of 4154 African American and Caucasian women who received mastectomy for definitive breast cancer treatment.

\section{Independent variables}

Sociodemographic variables obtained from the BJC Cancer Registry included age at diagnosis, race, and type of insurance. Age was dichotomized as $\leq 55$ and $>55$ years and three race categories were present in the Registry, African American, Asian, and Caucasian. Type of insurance was categorized as public (Medicaid, Medicare, Veterans' Affairs, Indian Health Service) or private [managed care, Health Maintenance Organization (HMO), Preferred Provider Organization (PPO), TRICARE, and fee for service]. Clinical variables analyzed included laterality of the breast tumor (right, left), tumor stage (stage 0/ductal carcinoma in situ (DCIS)-2, stage 3-4), tumor grade (grade 1-2, grade 3-4), estrogen receptor (ER) status (positive, negative), progesterone receptor (PR) status (positive, negative), human epidermal growth factor receptor 2 (HER2) status (positive, negative), triple negative status (no, yes). Triple negative status was only determined in women with expression results for ER, PR, and HER2.

Variables related to breast cancer treatment included type of mastectomy [total/simple, modified radical, radi$\mathrm{cal} /$ extended radical, skin/nipple-sparing, mastectomy not otherwise specified (NOS)], laterality of the mastectomy (unilateral, bilateral), receipt of adjuvant radiation (yes, no), receipt of adjuvant chemotherapy (yes, no), receipt of adjuvant hormonal therapy (yes, no), and receipt of breast reconstruction (yes, no). We also 
assessed the type of breast reconstruction (tissue expanders/implants, autologous flap, autologous flap and tissue expanders/implants, reduction mammoplasty, scar revision (Y-plasty), reconstruction NOS. The placement of tissue expanders was considered implant-based reconstruction. The primary outcome of interest was receipt of breast reconstruction of the diseased breast after definitive mastectomy for breast cancer treatment.

\section{Statistical analysis}

We first summarized each variable as follows: continuous variables were described by mean and standard deviation and categorical variables were summarized using frequencies and percentages. Independent variables that were significantly associated $(\mathrm{p}<0.05)$ with the receipt of breast reconstruction in Chi squared analysis were examined in unadjusted logistic regression models. Variables with $\mathrm{p}$ values $<0.1$ in the unadjusted models were incorporated into the final multivariable logistic regression model. Adjusted odds ratios, $95 \%$ confidence intervals, and $\mathrm{p}$ values were reported for regression analysis. All analysis was performed with Stata SE Version 12 (College Station, TX, USA), statistical significance was assessed as a $\mathrm{p}$ value $<0.05$.

\section{Results}

Sociodemographic and clinical characteristics are displayed in Table 1. The mean age of women in the sample was 55 years old. The majority of women $(80 \%$, $\mathrm{n}=3332)$ were Caucasian. Over half $(58 \%, \mathrm{n}=1975)$ of the women in the sample had private insurance, while $42 \%(\mathrm{n}=1454)$ had public insurance. Most women presented with tumors that were stage $0 /$ DCIS, 1 , or $2(81 \%$, $\mathrm{n}=3019)$ and grade 1 or $2(59 \%, \mathrm{n}=2314)$. Hormone receptor expression was also favorable; approximately $74 \%(n=2706)$ and $64 \%(n=2316)$ of the sample presented with ER positive or PR positive tumors, respectively. Twenty percent $(n=206)$ of the women presented with HER2 positive tumors and $12 \%(\mathrm{n}=128)$ presented with triple negative tumors. Nearly $80 \%(n=3243)$ of the sample received unilateral mastectomy as definitive breast cancer surgery. The most common type of mastectomy was total/simple mastectomy $(52 \%, \mathrm{n}=2148)$, followed by modified radical mastectomy $(40 \%, \mathrm{n}=1636)$. Six percent $(n=267)$ of the sample received skin-sparing or nipple-sparing mastectomies. Less than half of the women $(46 \%, \mathrm{n}=1876)$ received adjuvant chemotherapy and $31 \%(n=1300)$ received adjuvant radiation. Approximately half of the women $(53 \%, \mathrm{n}=2164)$ received adjuvant hormonal therapy.

The breast reconstruction rate and types of reconstructive surgery are displayed in Table 2 . The breast reconstruction rate of this sample was $54 \%(n=2227)$. Over half of the women $(\mathrm{n}=990)$ received placement of a tissue expander/implant for reconstruction. Women also underwent reconstruction NOS ( $39 \%, \mathrm{n}=762)$, autologous flap $(7 \%, \mathrm{n}=144)$, and combined autologous flap and placement of a tissue expander/implant for reconstruction $(2 \%, \mathrm{n}=32)$. Reduction mammoplasty $(0.2 \%$, $\mathrm{n}=3)$ and scar revision (Y-plasty) $(0.5 \%, \mathrm{n}=9)$ were performed in $<1 \%$ of women.

The results of the multivariable logistic regression are displayed in Table 3. In adjusted analysis, the sociodemographic factors that significantly predicted breast reconstruction were age, type of insurance, and race. Women aged 55 years or older where $65 \%$ less likely (aOR 0.35 ; $95 \%$ CI $0.29-0.42, \mathrm{p}<0.01)$ to receive breast reconstruction than women under the age of 55 . Women with public insurance were $55 \%$ less likely (aOR 0.45, $95 \%$ CI $0.38-0.54, \mathrm{p}<0.01)$ to receive breast reconstruction than women who had private insurance. African American women were $30 \%$ less likely (aOR $0.70,95 \% \mathrm{CI}$ $0.56-0.87, \mathrm{p}<0.01)$ to receive breast reconstruction than Caucasian women.

Tumor stage was significantly associated the receipt of breast reconstruction in this sample. Women with stage 3-stage 4 tumors were $40 \%$ less likely (aOR 0.60 , $95 \%$ CI 0.47-0.76, p < 0.01) to receive breast reconstruction compared to women with stage 0/DCIS-stage 2 tumors. Treatment factors significantly associated with the receipt of breast reconstruction included laterality of definitive mastectomy and receipt of adjuvant radiation therapy. Women who received unilateral mastectomy were $63 \%$ less likely (aOR $0.37,95 \%$ CI $0.30-0.46$, $\mathrm{p}<0.01)$ to receive breast reconstruction than women who received bilateral mastectomy. Women who received adjuvant radiation therapy were $28 \%$ less likely (aOR 0.72 ; $95 \%$ CI $0.59-0.89, \mathrm{p}=<0.01$ ) to receive breast reconstruction than women who did not receive adjuvant radiation therapy. PR status (aOR 0.87, 95 \% CI $0.87-$ $1.03, \mathrm{p}=0.12$ ) and receipt of adjuvant chemotherapy (aOR 0.72, $95 \%$ CI 0.59-0.89, $\mathrm{p}=0.55$ ) were not significantly associated breast reconstruction in this sample.

\section{Discussion}

The breast reconstruction rate $(54 \%)$ in this sample is high compared to the rates in population-based studies, which range from 5 to $29 \%$ (Platt et al. 2011; Wilkins and Alderman 2004), but is consistent with previously reported rates for this and other NCI-CCCs (Christian et al. 2006; Connors et al. 2014; Elmore et al. 2012; Greenberg et al. 2011; Mitchem et al. 2008; Tseng et al. 2004). Most (52\%) women in this sample received implant-based reconstruction, which is consistent previous studies at Siteman Cancer Center (Connors et al. 2014; Elmore et al. 2012; Mitchem et al. 2008), reflecting 
Table 1 Sociodemographic and clinical factors of women treated with mastectomy for breast cancer at the Siteman Cancer Center from 2000 to 2012

\begin{tabular}{|c|c|c|c|}
\hline Variable & Mean & SD & $\mathrm{N}$ \\
\hline \multicolumn{4}{|l|}{ Sociodemographics } \\
\hline \multirow[t]{2}{*}{ Age at diagnosis } & 55 & 13 & 4154 \\
\hline & Frequency & $\%$ & $\mathbf{N}$ \\
\hline \multicolumn{4}{|l|}{ Race } \\
\hline African American & 822 & 20 & \multirow[t]{2}{*}{4154} \\
\hline Caucasian & 3332 & 80 & \\
\hline \multicolumn{4}{|l|}{ Age (years) } \\
\hline$<55$ & 2018 & 49 & \multirow[t]{2}{*}{4154} \\
\hline$\geq 55$ & 2136 & 51 & \\
\hline \multicolumn{4}{|l|}{ Type of insurance } \\
\hline Private $^{a}$ & 1975 & 58 & \multirow[t]{2}{*}{3429} \\
\hline Public ${ }^{b}$ & 1454 & 42 & \\
\hline \multicolumn{4}{|l|}{ Clinical factors } \\
\hline \multicolumn{4}{|l|}{ Tumor stage } \\
\hline Stage 0/DCIS-2 & 3019 & 81 & \multirow[t]{2}{*}{3709} \\
\hline Stage 3-4 & 690 & 19 & \\
\hline \multicolumn{4}{|l|}{ Tumor grade } \\
\hline Grade 1-2 & 2314 & 59 & \multirow[t]{2}{*}{3903} \\
\hline Grade 3-4 & 1589 & 41 & \\
\hline \multicolumn{4}{|l|}{ ER status } \\
\hline Positive & 2706 & 74 & \multirow[t]{2}{*}{3633} \\
\hline Negative & 927 & 26 & \\
\hline \multicolumn{4}{|l|}{ PR status } \\
\hline Positive & 2316 & 64 & \multirow[t]{2}{*}{3619} \\
\hline Negative & 1303 & 36 & \\
\hline \multicolumn{4}{|l|}{ HER2 status } \\
\hline Positive & 206 & 20 & \multirow[t]{2}{*}{1016} \\
\hline Negative & 810 & 79 & \\
\hline \multicolumn{4}{|l|}{ Triple negative cancer } \\
\hline No & 941 & 88 & \multirow[t]{2}{*}{1069} \\
\hline Yes & 128 & 12 & \\
\hline \multicolumn{4}{|l|}{ Laterality of mastectomy } \\
\hline Bilateral & 903 & 22 & \multirow[t]{2}{*}{4146} \\
\hline Unilateral & 3243 & 78 & \\
\hline \multicolumn{4}{|l|}{ Type of definitive mastectomy } \\
\hline Total/simple & 2148 & 52 & 4126 \\
\hline Modified radical & 1636 & 40 & \\
\hline $\begin{array}{l}\text { Radical/extended modified } \\
\text { radical }\end{array}$ & 58 & 1 & \\
\hline Skin/nipple-sparing & 267 & 6 & \\
\hline Mastectomy NOS & 20 & 0.5 & \\
\hline Received adjuvant chemother & erapy & & \\
\hline No & 2233 & 54 & 4109 \\
\hline Yes & 1876 & 46 & \\
\hline Received adjuvant radiation & & & \\
\hline No & 2854 & 69 & 4154 \\
\hline Yes & 1300 & 31 & \\
\hline
\end{tabular}

Table 1 continued

\begin{tabular}{lccc}
\hline & Frequency & $\%$ & N \\
\hline Received adjuvant hormonal therapy & & \\
No & 1894 & 47 & 4058 \\
Yes & 2164 & 53 & \\
\hline
\end{tabular}

$D C I S$ ductal carcinoma in situ, $E R$ estrogen receptor, $P R$ progesterone receptor, HER2 human epidermal growth factor receptor 2, NOS not otherwise specified

a Private insurance included: managed care, HMO, PPO, TRICARE, fee for service

b Public insurance included: Medicaid, Medicare, Veterans' Affairs, Indian Health Service

the national trend of increasing rates of implant-based breast reconstruction (Albornoz et al. 2012, 2013; Jagsi et al. 2014). Less than $1 \%$ of women received reduction mammoplasty or scar revision (Y-plasty).

Age is one of the most consistent predictors of receiving breast reconstruction (Platt et al. 2011). Our results are consistent with previous studies that report older women are less likely to receive breast reconstruction (Agarwal et al. 2011; Alderman et al. 2003, 2009; Chen et al. 2009; Desch et al. 1999; Elmore et al. 2012; Giladi et al. 2015; Greenberg et al. 2008; Hershman et al. 2012; Iskandar et al. 2015; Jackson et al. 2008; Joslyn 2005; Kruper et al. 2011b; Mahmoudi et al. 2015; Maly et al. 2009; Morrow et al. 2001, 2005, 2014; Polednak 1999; Preminger et al. 2012; Reuben et al. 2009; Rosson et al. 2008; Shippee et al. 2014; Tseng et al. 2010; Yang et al. 2013a). Studies suggest that older women may choose not to have breast reconstruction because they are less disturbed by the prospect of breast loss or more worried about surgical morbidity and complications (Alderman et al. 2003; Morrow et al. 2005; Reaby et al. 1994; Wolfswinkel et al. 2013). Similar to previous studies, women with public insurance were significantly less likely to receive breast reconstruction than those with private insurance (Alderman et al. 2009; Bradley et al. 2012; Christian et al. 2006; Kruper et al. 2011a, b; Mahmoudi et al. 2015; Morrow et al. 2014; Shippee et al. 2014; Yang et al. 2013a). Lack of access to facilities with qualified plastic surgeons and lower payer reimbursement for services may play a role in this relationship (Christian et al. 2006; Kruper et al. 2011a; Preminger et al. 2012). Additionally, for women with public insurance, lower socioeconomic status may serve as a barrier to breast reconstruction because these women must be more attuned to the out-of-pocket costs associated with the procedures, loss of days from work, cost of transportation, and costs of childcare (Katz et al. 2005; Wilkins and Alderman 2004). Siteman Cancer Center has increased its efforts to inform women of available financial, social, and other support services to circumvent these barriers (Fayanju et al. 2013). It is likely that other NCI-CCCs have done the same. 
Table 2 Breast reconstruction rate and type of breast reconstructive surgery of women treated with mastectomy for breast cancer at the Siteman Cancer Center from 2000 to 2012

\begin{tabular}{lccc}
\hline Variable & Frequency & $\%$ & N \\
\hline Received breast reconstruction & & 54 & 4152 \\
Yes & 2227 & 46 & \\
No & 1925 & & \\
Type of breast reconstruction & & 52 & 1938 \\
Tissue expander/implant & 990 & 7 & \\
Autologous flap & 144 & 2 & \\
Autologous flap and tissue expander/ & 32 & & \\
$\quad$ implant & & 0.2 & \\
Reduction mammoplasty & 3 & 0.5 & \\
Scar revision (Y-plasty) & 9 & 39 & \\
Reconstruction NOS & 760 & & \\
\hline
\end{tabular}

NOS not otherwise specified

Stage of disease is considered the most predictive clinical factor of receiving breast reconstruction (Platt et al. 2011). In this sample, women with more advanced tumor stages were significantly less likely to receive breast reconstruction. Many studies report women with earlier stages are more likely to receive breast reconstruction (Agarwal et al. 2011; Alderman et al. 2003; Bradley et al. 2012; Chen et al. 2009; Christian et al. 2006; Enewold et al. 2014; Iskandar et al. 2015; Joslyn 2005; Morrow et al. 2001, 2005; Polednak 1999, 2000; Tseng et al. 2004). Although higher stage of disease is not a contraindication for breast reconstruction, women and/or their physicians may prioritize adjuvant treatment above reconstructive procedures (Agarwal et al. 2011; Alderman et al. 2007). Tumor grade did not significantly predict breast reconstruction in this or previous studies (Enewold et al. 2014; Tseng et al. 2010).

The type of breast cancer treatment received correlates with the receipt breast reconstruction (Jagsi et al. 2014). Women who received unilateral mastectomy were significantly less likely to receive reconstruction. This finding is consistent with previous studies (Elmore et al. 2012; Hershman et al. 2012; Iskandar et al. 2015; Jagsi et al. 2014; Joslyn 2005; Preminger et al. 2012; Tseng et al. 2010). Women who have bilateral mastectomies are more likely to be referred to plastic surgeons for breast reconstruction consultations (Preminger et al. 2012) and it has been suggested that women who are highly motivated to receive breast reconstruction may choose bilateral mastectomies, even when it is not clinically indicated, to achieve better symmetry after reconstruction (Tseng et al. 2010). Receipt of adjuvant chemotherapy was not significantly associated with breast reconstruction in our sample. Studies have reported conflicting data on the role of chemotherapy in breast reconstruction. Some studies have reported that receiving neoadjuvant or adjuvant chemotherapy reduces the odds of receiving breast reconstruction (Alderman et al. 2009; Wolfswinkel et al. 2013), while others report that it did not significantly affect the odds of receiving breast reconstruction (Elmore et al. 2012; Enewold et al. 2014; Maly et al. 2009; Morrow et al. 2014). More work is needed to clarify the role of chemotherapy on the receipt of breast reconstruction. Similar to results found in other studies, we found that women who received adjuvant radiation therapy were less likely to receive breast reconstruction (Agarwal et al. 2011; Alderman et al. 2003, 2009; Chen et al. 2009; Enewold et al. 2014; Greenberg et al. 2008; Jagsi et al. 2014; Tseng et al. 2010). Patients who require radiation therapy are less likely to be referred to plastic surgeons for breast reconstruction reflecting concerns on the part of physicians that radiation therapy will negatively impact the results of breast reconstruction (Greenberg et al. 2008; Jagsi et al. 2014). There are currently no uniform guidelines to inform the use of breast reconstruction after radiation therapy and more research is needed to determine the effect of radiation therapy on breast reconstruction outcomes (Elmore et al. 2012; Jagsi et al. 2014).

Even when controlling for sociodemographic and clinical factors, African American women in this sample were $30 \%$ less likely to receive breast reconstruction than their Caucasian counterparts. Although these results are consistent with previous studies (Agarwal et al. 2011; Alderman et al. 2003, 2006; Bradley et al. 2012; Greenberg et al. 2008; Hershman et al. 2012; Jackson et al. 2008; Joslyn 2005; Katz et al. 2005; Kruper et al. 2011a, b, 2013; Lang et al. 2013; Mahmoudi et al. 2015; Morrow et al. 2001, 2014; Offodile et al. 2015; Reuben et al. 2009; Rosson et al. 2008; Shippee et al. 2014; Sisco et al. 2012; Tseng et al. 2004, 2010; Yang et al. 2013a, b), they bolster previous work on the topic by virtue of the relatively high percentage (20\%) of African American women in the sample. Yet our results are contrary to other studies that report no significant contribution of race on breast cancer rates, despite trends towards African Americans having lesser odds of breast reconstruction (Alderman et al. 2009; Chen et al. 2009; Christian et al. 2006; Elmore et al. 2012; Enewold et al. 2014; Iskandar et al. 2015; Kruper et al. 2011b; Maly et al. 2009; Polednak 1999, 2001; Sisco et al. 2012; Wolfswinkel et al. 2013). To our knowledge, only one study has reported that African American women were significantly more likely to receive breast reconstruction than Caucasian women (Giladi et al. 2015). This may have been due to the fact that this study focused on a Medicaid population, with an overall low 
Table 3 Multivariable logistic regression of breast reconstruction in women treated with mastectomy for breast cancer at the Siteman Cancer Center from 2000 to 2012 ( $N=2809$ )

\begin{tabular}{|c|c|c|c|}
\hline Variable & aOR & $95 \% \mathrm{Cl}$ & $\mathrm{p}$ value \\
\hline \multicolumn{4}{|l|}{ Age $^{*}$} \\
\hline$<55$ & 1.00 & - & - \\
\hline$\geq 55$ & 0.35 & $0.29-0.42$ & $<0.01$ \\
\hline \multicolumn{4}{|l|}{ Race $^{*}$} \\
\hline Caucasian & 1.00 & - & - \\
\hline African American & 0.70 & $0.56-0.87$ & $<0.01$ \\
\hline \multicolumn{4}{|l|}{ Insurance ${ }^{*}$} \\
\hline Private $^{a}$ & 1.00 & - & - \\
\hline Public ${ }^{b}$ & 0.45 & $0.38-0.54$ & $<0.01$ \\
\hline \multicolumn{4}{|l|}{ Tumor stage* } \\
\hline Stage 0/DCIS-2 & 1.00 & - & - \\
\hline Stage 3-4 & 0.60 & $0.47-0.76$ & $<0.01$ \\
\hline \multicolumn{4}{|l|}{ PR status } \\
\hline Positive & 1.00 & - & - \\
\hline Negative & 0.87 & $0.73-1.03$ & 0.12 \\
\hline \multicolumn{4}{|c|}{ Laterality of mastectomy* } \\
\hline Bilateral & 1.00 & - & - \\
\hline Unilateral & 0.37 & $0.30-0.46$ & $<0.01$ \\
\hline \multicolumn{4}{|c|}{ Receipt of adjuvant chemotherapy } \\
\hline No & 1.00 & - & - \\
\hline Yes & 1.06 & $0.87-1.30$ & 0.55 \\
\hline \multicolumn{4}{|c|}{ Receipt of adjuvant radiation therapy* } \\
\hline No & 1.00 & - & - \\
\hline Yes & 0.72 & $0.59-0.89$ & $<0.01$ \\
\hline
\end{tabular}

$D C I S$ ductal carcinoma in situ, $P R$ progesterone receptor

* Statistically significant variable

a Private insurance included: managed care, HMO, PPO, TRICARE, fee for service

b Public insurance included: Medicaid, Medicare, Veterans' Affairs, Indian Health Service

income. Studies from NCI-CCCs have also produced conflicting results on the role of race on the receipt of breast reconstruction. Race did not significantly affect the odds of receiving breast reconstruction in two studies (Christian et al. 2006; Elmore et al. 2012), while Tseng et al. (2004) found that African American women were $66 \%$ less likely to receive breast reconstruction compared to Caucasian women. The reasons for variations on the role of race on the receipt of breast reconstruction are unclear but may reflect differences in study populations, geographic location, use of different socioeconomic variables, or limited range of patient-related factors (Christian et al. 2006; Wolfswinkel et al. 2013). The results of this and previous studies raise the need for more research to examine racial/ethnic disparities in breast reconstruction across various types of healthcare institutions.

\section{Limitations}

This study has several limitations. It is focused on a single comprehensive cancer center which limits its generalizability to other healthcare institutions or geographical locations. Age, race, and insurance status were the only sociodemographic variables in the BJH Cancer Registry. Therefore, we were unable to fully examine the role of socioeconomic status on breast reconstruction in our analysis and used insurance status as a proxy for socioeconomic status. The Registry lacked information about other determinants of breast reconstruction such as marital status (Agarwal et al. 2011; Chen et al. 2009; Elmore et al. 2012; Hershman et al. 2012; Joslyn 2005) and comorbidities (Chen et al. 2009; Hershman et al. 2012; Reuben et al. 2009; Yang et al. 2013a), including diabetes (Preminger et al. 2012), and obesity (Chen et al. 2009; Christian et al. 2006; Greenberg et al. 2008; Preminger et al. 2012; Wolfswinkel et al. 2013). The strengths of this study included the ability to use a large administrative database to quantify the rate and determinants of breast reconstruction after mastectomy in a NCI-CCC. The large sample of African American and Caucasian women allowed for multivariable regression analysis that incorporated sociodemographic and clinical determinants of breast reconstruction.

\section{Conclusion}

We found that Siteman Cancer Center had a relatively high breast reconstruction rate between 2000 and 2012 . After adjusting for sociodemographic and clinical factors, women who were over the age of 55 , had public insurance, were treated with unilateral mastectomy, or received adjuvant radiation therapy were significantly less likely to receive breast reconstruction. These findings mirror many of the most common predictors of breast reconstruction previously reported (Brennan and Spillane 2013; Platt et al. 2011; Wilkins and Alderman 2004) and extend the findings of previous studies at Siteman Cancer Center (Connors et al. 2014; Elmore et al. 2012; Sharma et al. 2015) with a larger sample size. Of particular interest was that African American women were $30 \%$ less likely to receive breast reconstruction at this NCICCC. The presence of racial disparities in specialized tertiary healthcare institutions suggests that factors outside of access and quality of care may play a role in breast reconstruction disparities. These breast reconstruction disparities have also be reported in Asian, Latina, and Middle Eastern women (Agarwal et al. 2011; Alderman et al. 2003, 2009; Hershman et al. 2012; Iskandar et al. 2015; Katz et al. 2005; Kruper et al. 2011a, b; Kruper et al. 2013; Lang et al. 2013; Mahmoudi et al. 2015; Maly et al. 2009; Offodile et al. 2015; Onega et al. 2014; Shippee et al. 2014; Tseng et al. 2004, 2010; Yang et al. 2013a, 2013b). It is therefore imperative to further examine and 
address the racial/ethnic disparities in breast reconstruction. Although not considered in this study, patient involvement in decision-making and personal preference may play important roles in breast reconstruction disparities (Greenberg et al. 2008). Few studies focus on these topics among minority women (Rubin et al. 2013). Future research is needed to further delineate the determinants of breast reconstruction disparities across a variety of healthcare institutions, focusing on the role of decisionmaking and personal preference in minority women. Only then can we develop multilevel interventions to ensure every breast cancer patient has equitable access to breast reconstruction and the improved quality of life it offers to breast cancer survivors.

\begin{abstract}
Abbreviations
BJH: Barnes-Jewish Hospital; DCIS: ductal carcinoma in situ; ER: estrogen receptor; HRPO: Human Research Protection Office; HER2: human epidermal growth factor receptor 2; HMO: Health Maintenance Organization; IRB: Institutional Review Board; NCI-CCC: National Cancer Institute-designated Comprehensive Cancer Center; ODS: Oncology Data Services; PPO: Preferred Provider Organization; PR: progesterone receptor; NOS: not otherwise specified.
\end{abstract}

\section{Authors' contributions}

SKC, MSG, TM, JM, and SG participated in study conception and design. SC and MG participated in the acquisition, analysis, and interpretation of the data. All authors participated in drafting and critical revision of the manuscript. All authors read and approved the final manuscript.

\section{Author details}

${ }^{1}$ Division of Public Health Sciences, Department of Surgery, Washington University in St. Louis School of Medicine, St. Louis, MO, USA. ${ }^{2}$ Division of Plastic and Reconstructive Surgery, Department of Surgery, Washington University in St. Louis School of Medicine, St. Louis, MO, USA. ${ }^{3}$ Division of Endocrine Oncologic Surgery, Department of Surgery, Washington University in St. Louis School of Medicine, St. Louis, MO, USA. ${ }^{4}$ George Warren Brown School of Social Work, Washington University in St. Louis, St. Louis, MO, USA.

\section{Acknowledgements}

We would like to thank Ms. Lori Grove, Tumor Registrar, at the Barnes-Jewish Hospital Cancer Registry and Dr. Cassandra Arroyo Johnson, Assistant Professor of Surgery, Division of Public Health Sciences, at Washington University in St. Louis School of Medicine for their technical assistance with this manuscript.

\section{Competing interests}

TM serves as a consultant for Acelity, Allegan, Plc., and Andrews Technologies, LLC; he has also received funding from Allergan, Plc. JM serves as a consultant for Genentech and Myriad Genetics, Inc. SKC, MG, and SG declare no competing interests.

\section{Ethics, consent and permissions}

All procedures performed in studies involving human participants have been approved by the appropriate institutional and/or national research ethics committee. The Human Research Protection Office (HRPO) and Institutional Review Board (IRB) at Washington University in St. Louis gave this study exempt status.

\section{Funding}

This study and manuscript preparation was funded with grants from the National Cancer Institute (U54CA153460, G. Colditz, PI) and the Barnes-Jewish Foundation of BJH Health Care

Received: 18 May 2016 Accepted: 20 May 2016

Published online: 02 July 2016
References

Agarwal S, Pappas L, Neumayer L, Agarwal J (2011) An analysis of immediate postmastectomy breast reconstruction frequency using the surveillance, epidemiology, and end results database. Breast J 17(4):352-358. doi:10.1111/j.1524-4741.2011.01105.x

Albornoz CR, Bach PB, Pusic AL, McCarthy CM, Mehrara BJ, Disa JJ, Cordeiro PG, Matros E (2012) The influence of sociodemographic factors and hospital characteristics on the method of breast reconstruction, including microsurgery: a U.S. population-based study. Plast Reconstr Surg 129(5):10711079. doi:10.1097/PRS.0b013e31824a29c5

Albornoz CR, Bach PB, Mehrara BJ, Disa JJ, Pusic AL, McCarthy CM, Cordeiro PG, Matros E (2013) A paradigm shift in U.S. breast reconstruction: increasing implant rates. Plast Reconstr Surg 131(1):15-23. doi:10.1097/ PRS.0b013e3182729cde

Alderman AK, McMahon L Jr, Wilkins EG (2003) The national utilization of immediate and early delayed breast reconstruction and the effect of sociodemographic factors. Plast Reconstr Surg 111(2):695-703. doi:10.1097/01.PRS.0000041438.50018.02 (Discussion 695-704)

Alderman AK, Wei Y, Birkmeyer JD (2006) Use of breast reconstruction after mastectomy following the Women's Health and Cancer Rights Act. JAMA 295(4):387-388. doi:10.1001/jama.295.4.387

Alderman AK, Hawley ST, Waljee J, Morrow M, Katz SJ (2007) Correlates of referral practices of general surgeons to plastic surgeons for mastectomy reconstruction. Cancer 109(9):1715-1720. doi:10.1002/cncr.22598

Alderman AK, Hawley ST, Janz NK, Mujahid MS, Morrow M, Hamilton AS, Graff JJ, Katz SJ (2009) Racial and ethnic disparities in the use of postmastectomy breast reconstruction: results from a population-based study. J Clin Oncol 27(32):5325-5330. doi:10.1200/JCO.2009.22.2455

Alderman AK, Hawley ST, Morrow M, Salem B, Hamilton A, Graff JJ, Katz S (2011) Receipt of delayed breast reconstruction after mastectomy: do women revisit the decision? Ann Surg Oncol 18(6):1748-1756. doi:10.1245/s10434-010-1509-y

Al-Ghazal SK, Sully L, Fallowfield L, Blamey RW (2000) The psychological impact of immediate rather than delayed breast reconstruction. Eur J Surg Oncol 26(1):17-19

Atisha D, Alderman AK, Lowery JC, Kuhn LE, Davis J, Wilkins EG (2008) Prospective analysis of long-term psychosocial outcomes in breast reconstruction: two-year postoperative results from the Michigan Breast Reconstruction Outcomes Study. Ann Surg 247(6):1019-1028. doi:10.1097/ SLA.0b013e3181728a5c

Bradley CJ, Dahman B, Shickle LM, Lee W (2012) Surgery wait times and specialty services for insured and uninsured breast cancer patients: does hospital safety net status matter? Health Serv Res 47(2):677-697. doi:10.1111/j.1475-6773.2011.01328.x

Brennan ME, Spillane AJ (2013) Uptake and predictors of post-mastectomy reconstruction in women with breast malignancy — systematic review. Eur J Surg Oncol 39(6):527-541. doi:10.1016/j.ejso.2013.02.021

Butler PD, Nelson JA, Fischer JP, Wink JD, Chang B, Fosnot J, Wu LC, Serletti JM (2015) Racial and age disparities persist in immediate breast reconstruction: an updated analysis of 48,564 patients from the 2005 to 2011 American College of Surgeons National Surgery Quality Improvement Program data sets. Am J Surg. doi:10.1016/j.amjsurg.2015.08.025

Chen JY, Malin J, Ganz PA, Ko C, Tisnado D, Tao ML, Timmer M, Adams $J$, Kahn KL (2009) Variation in physician-patient discussion of breast reconstruction. J Gen Intern Med 24(1):99-104. doi:10.1007/ s1 1606-008-0855-y

Christian CK, Niland J, Edge SB, Ottesen RA, Hughes ME, Theriault R, Wilson J, Hergrueter CA, Weeks JC (2006) A multi-institutional analysis of the socioeconomic determinants of breast reconstruction: a study of the National Comprehensive Cancer Network. Ann Surg 243(2):241-249. doi:10.1097/01.sla.0000197738.63512.23

Connors SK, Goodman MS, Noel L, Chavakula NN, Butler D, Kenkel S, Oliver C, McCullough I, Gehlert S (2014) Breast cancer treatment among African American women in North St. Louis, Missouri. J Urban Health. doi:10.1007/s11524-014-9884-5

Desch CE, Penberthy LT, Hillner BE, McDonald MK, Smith TJ, Pozez AL, Retchin SM (1999) A sociodemographic and economic comparison of breast reconstruction, mastectomy, and conservative surgery. Surgery 125(4):441-447

Elmore L, Myckatyn TM, Gao F, Fisher CS, Atkins J, Martin-Dunlap TM, Margenthaler JA (2012) Reconstruction patterns in a single institution cohort 
of women undergoing mastectomy for breast cancer. Ann Surg Oncol 19(10):3223-3229. doi:10.1245/s10434-012-2530-0

Eltahir Y, Werners LL, Dreise MM, van Emmichoven IA, Jansen L, Werker PM, de Bock GH (2013) Quality-of-life outcomes between mastectomy alone and breast reconstruction: comparison of patient-reported BREAST-Q and other health-related quality-of-life measures. Plast Reconstr Surg 132(2):201e-209e. doi:10.1097/PRS.0b013e31829586a7

Enewold LR, McGlynn KA, Zahm SH, Poudrier J, Anderson WF, Shriver CD, Zhu K (2014) Breast reconstruction after mastectomy among Department of Defense beneficiaries by race. Cancer 120(19):3303-3309. doi:10.1002/ cncr.28806

Fayanju OM, Jeffe DB, Elmore L, Ksiazek DN, Margenthaler JA (2013) Patient and process factors associated with late-stage breast cancer diagnosis in safety-net patients: a pilot prospective study. Ann Surg Oncol 20(3):723732. doi:10.1245/s10434-012-2558-1

Giladi AM, Chung KC, Aliu O (2015) Changes in use of autologous and prosthetic postmastectomy reconstruction after Medicaid expansion in New York state. Plast Reconstr Surg 135(1):53-62. doi:10.1097/ PRS.0000000000000808

Greenberg CC, Schneider EC, Lipsitz SR, Ko CY, Malin JL, Epstein AM, Weeks JC, Kahn KL (2008) Do variations in provider discussions explain socioeconomic disparities in postmastectomy breast reconstruction? J Am Coll Surg 206(4):605-615. doi:10.1016/j.jamcollsurg.2007.11.017

Greenberg CC, Lipsitz SR, Hughes ME, Edge SB, Theriault R, Wilson JL, Carter WB, Blayney DW, Niland J, Weeks JC (2011) Institutional variation in the surgical treatment of breast cancer: a study of the NCCN. Ann Surg 254(2):339-345. doi:10.1097/SLA.0b013e3182263bb0

Harcourt DM, Rumsey NJ, Ambler NR, Cawthorn SJ, Reid CD, Maddox PR, Kenealy JM, Rainsbury RM, Umpleby HC (2003) The psychological effect of mastectomy with or without breast reconstruction: a prospective, multicenter study. Plast Reconstr Surg 111(3):1060-1068. doi:10.1097/01. PRS.0000046249.33122.76

Hershman DL, Richards CA, Kalinsky K, Wilde ET, Lu YS, Ascherman JA, Neugut Al, Wright JD (2012) Influence of health insurance, hospital factors and physician volume on receipt of immediate post-mastectomy reconstruction in women with invasive and non-invasive breast cancer. Breast Cancer Res Treat 136(2):535-545. doi:10.1007/s10549-012-2273-4

Iskandar ME, Dayan E, Lucido D, Samson W, Sultan M, Dayan JH, Boolbol SK, Smith ML (2015) Factors influencing incidence and type of postmastectomy breast reconstruction in an urban multidisciplinary cancer center. Plast Reconstr Surg 135(2):270e-276e. doi:10.1097/ PRS.0000000000000888

Jackson LC, Camacho F, Levine EA, Anderson RT, Stewart JH (2008) Patterns of care analysis among women with ductal carcinoma in situ in North Carolina. Am J Surg 195(2):164-169. doi:10.1016/j. amjsurg.2007.10.001

Jagsi R, Jiang J, Momoh AO, Alderman A, Giordano SH, Buchholz TA, Kronowitz SJ, Smith BD (2014) Trends and variation in use of breast reconstruction in patients with breast cancer undergoing mastectomy in the United States. J Clin Oncol 32(9):919-926. doi:10.1200/JCO.2013.52.2284

Joslyn SA (2005) Patterns of care for immediate and early delayed breast reconstruction following mastectomy. Plast Reconstr Surg 115(5):1289-1296

Katz SJ, Lantz PM, Paredes Y, Janz NK, Fagerlin A, Liu L, Deapen D (2005) Breast cancer treatment experiences of Latinas in Los Angeles County. Am J Public Health 95(12):2225-2230. doi:10.2105/AJPH.2004.057950

Kruper L, Holt A, Xu XX, Duan L, Henderson K, Bernstein L, Ellenhorn J (2011a) Disparities in reconstruction rates after mastectomy: patterns of care and factors associated with the use of breast reconstruction in Southern California. Ann Surg Oncol 18(8):2158-2165. doi:10.1245/s10434-011-1580-z

Kruper L, Xu X, Henderson K, Bernstein L (2011b) Disparities in reconstruction rates after mastectomy for ductal carcinoma in situ (DCIS): patterns of care and factors associated with the use of breast reconstruction for DCIS compared with invasive cancer. Ann Surg Oncol 18(11):3210-3219. doi:10.1245/s10434-011-2010-y

Kruper L, Xu XX, Henderson K, Bernstein L Chen SL (2013) Utilization of mastectomy and reconstruction in the outpatient setting. Ann Surg Oncol 20(3):828-835. doi:10.1245/s10434-012-2661-3

Lang JE, Summers DE, Cui H, Carey JN, Viscusi RK, Hurst CA, Waer AL, Ley ML, Sener SF, Vijayasekaran A (2013) Trends in post-mastectomy reconstruction: a SEER database analysis. J Surg Oncol 108(3):163-168. doi:10.1002/jso.23365

Mahmoudi E, Giladi AM, Wu L, Chung KC (2015) Effect of federal and state policy changes on racial/ethnic variation in immediate postmastectomy breast reconstruction. Plast Reconstr Surg 135(5):1285-1294. doi:10.1097/ PRS.0000000000001149

Maly RC, Liu Y, Kwong E, Thind A, Diamant AL (2009) Breast reconstructive surgery in medically underserved women with breast cancer: the role of patient-physician communication. Cancer 115(20):4819-4827. doi:10.1002/cncr.24510

Merchant SJ, Goldstein L, Kruper LL (2015) Patterns and trends in immediate postmastectomy reconstruction in California: complications and unscheduled readmissions. Plast Reconstr Surg 136(1):10e-19e. doi:10.1097/PRS.0000000000001326

Mitchem J, Herrmann D, Margenthaler JA, Aft RL (2008) Impact of neoadjuvant chemotherapy on rate of tissue expander/implant loss and progression to successful breast reconstruction following mastectomy. Am J Surg 196(4):519-522. doi:10.1016/j.amjsurg.2008.06.016

Morrow M, Scott SK, Menck HR, Mustoe TA, Winchester DP (2001) Factors influencing the use of breast reconstruction postmastectomy: a National Cancer Database study. J Am Coll Surg 192(1):1-8

Morrow M, Mujahid M, Lantz PM, Janz NK, Fagerlin A, Schwartz K, Liu L, Deapen D, Salem B, Lakhani I, Katz SJ (2005) Correlates of breast reconstruction: results from a population-based study. Cancer 104(11):23402346. doi:10.1002/cncr.21444

Morrow M, Li Y, Alderman AK, Jagsi R, Hamilton AS, Graff JJ, Hawley ST, Katz SJ (2014) Access to breast reconstruction after mastectomy and patient perspectives on reconstruction decision making. JAMA Surg 149(10):10151021. doi:10.0110/jamasurg.2014.548

Offodile AC 2nd, Tsai TC, Wenger JB, Guo L (2015) Racial disparities in the type of postmastectomy reconstruction chosen. J Surg Res 195(1):368-376. doi:10.1016/j.jss.2015.01.013

Onega T, Weiss J, Kerlikowske K, Wernli K, Buist DS, Henderson LM, Goodrich M, Alford-Teaster J, Virnig B, Tosteson AN, DeMartini W, Hubbard R (2014) The influence of race/ethnicity and place of service on breast reconstruction for Medicare beneficiaries with mastectomy. Springerplus 3:416. doi:10.1186/2193-1801-3-416

Platt J, Baxter N, Zhong T (2011) Breast reconstruction after mastectomy for breast cancer. Can Med Assoc J 183(18):2109-2116. doi:10.1503/ cmaj.110513

Polednak AP (1999) Postmastectomy breast reconstruction in Connecticut: trends and predictors. Plast Reconstr Surg 104(3):669-673

Polednak AP (2000) Geographic variation in postmastectomy breast reconstruction rates. Plast Reconstr Surg 106(2):298-301

Polednak AP (2001) How frequent is postmastectomy breast reconstructive surgery? A study linking two statewide databases. Plast Reconstr Surg 108(1):73-77

Preminger BA, Trencheva K, Chang CS, Chiang A, El-Tamer M, Ascherman J, Rohde C (2012) Improving access to care: breast surgeons, the gatekeepers to breast reconstruction. J Am Coll Surg 214(3):270-276. doi:10.1016/j. jamcollsurg.2011.11.014

Reaby LL, Hort LK, Vandervord J (1994) Body image, self-concept, and selfesteem in women who had a mastectomy and either wore an external breast prosthesis or had breast reconstruction and women who had not experienced mastectomy. Health Care Women Int 15(5):361-375. doi:10.1080/07399339409516129

Reuben BC, Manwaring J, Neumayer LA (2009) Recent trends and predictors in immediate breast reconstruction after mastectomy in the United States. Am J Surg 198(2):237-243. doi:10.1016/j.amjsurg.2008.11.034

Rosson GD, Singh NK, Ahuja N, Jacobs LK, Chang DC (2008) Multilevel analysis of the impact of community vs patient factors on access to immediate breast reconstruction following mastectomy in Maryland. Arch Surg 143(11):1076-1081. doi:10.1001/archsurg.143.11.1076 (Discussion 1081)

Rowland JH, Holland JC, Chaglassian T, Kinne D (1993) Psychological response to breast reconstruction. Expectations for and impact on postmastectomy functioning. Psychosomatics 34(3):241-250. doi:10.1016/ S0033-3182(93)71886-1

Rowland JH, Desmond KA, Meyerowitz BE, Belin TR, Wyatt GE, Ganz PA (2000) Role of breast reconstructive surgery in physical and emotional outcomes among breast cancer survivors. J Natl Cancer Inst 92(17):1422-1429 
Rubin LR, Chavez J, Alderman A, Pusic AL (2013) 'Use what God has given me': difference and disparity in breast reconstruction. Psychol Health 28(10):1099-1120. doi:10.1080/08870446.2013.782404

Sharma K, Grant D, Myckatyn TM (2015) The impact of race on choice of postmastectomy reconstruction: is there a healthcare disparity? Plast Reconstr Surg 136(4 Suppl):114-115. doi:10.1097/01.prs.0000472421.19798.cb

Shippee TP, Kozhimannil KB, Rowan K, Virnig BA (2014) Health insurance coverage and racial disparities in breast reconstruction after mastectomy. Women's Health Issues 24(3):e261-e269. doi:10.1016/j.whi.2014.03.001

Sisco M, Du H, Warner JP, Howard MA, Winchester DP, Yao K (2012) Have we expanded the equitable delivery of postmastectomy breast reconstruction in the new millennium? Evidence from the National Cancer Data Base. J Am Coll Surg 215(5):658-666. doi:10.1016/j.jamcollsurg.2012.07.008 (Discussion 666)

Tseng JF, Kronowitz SJ, Sun CC, Perry AC, Hunt KK, Babiera GV, Newman LA, Singletary SE, Mirza NQ, Ames FC, Meric-Bernstam F, Ross MI, Feig BW, Robb GL, Kuerer HM (2004) The effect of ethnicity on immediate reconstruction rates after mastectomy for breast cancer. Cancer 101(7):15141523. doi:10.1002/cncr.20529

Tseng WH, Stevenson TR, Canter RJ, Chen SL, Khatri VP, Bold RJ, Martinez SR (2010) Sacramento area breast cancer epidemiology study: use of postmastectomy breast reconstruction along the rural-to-urban continuum. Plast Reconstr Surg 126(6):1815-1824. doi:10.1097/ PRS.0b013e3181f444bc
Wexelman B, Schwartz JA, Lee D, Estabrook A, Ma AM (2014) Socioeconomic and geographic differences in immediate reconstruction after mastectomy in the United States. Breast J 20(4):339-346. doi:10.1111/tbj.12274

Wilkins EG, Alderman AK (2004) Breast reconstruction practices in North America: current trends and future priorities. Semin Plast Surg 18(2):149-155. doi:10.1055/s-2004-829049

Wilkins EG, Cederna PS, Lowery JC, Davis JA, Kim HM, Roth RS, Goldfarb S, Izenberg PH, Houin HP, Shaheen KW (2000) Prospective analysis of psychosocial outcomes in breast reconstruction: one-year postoperative results from the Michigan Breast Reconstruction Outcome Study. Plast Reconstr Surg 106(5):1014-1025 (Discussion 1026-1017)

Wolfswinkel EM, Lopez SN, Weathers WM, Qashqai S, Wang T, Hilsenbeck SG, Rimawi MF, Heller L (2013) Predictors of post-mastectomy reconstruction in an underserved population. J Plast Reconstr Aesthet Surg 66(6):763769. doi:10.1016/j.bjps.2013.02.018

Yang RL, Newman AS, Lin IC, Reinke CE, Karakousis GC, Czerniecki BJ, Wu LC, Kelz RR (2013a) Trends in immediate breast reconstruction across insurance groups after enactment of breast cancer legislation. Cancer 119(13):2462-2468. doi:10.1002/cncr.28050

Yang RL, Newman AS, Reinke CE, Lin IC, Karakousis GC, Czerniecki BJ, Wu LC, Kelz RR (2013b) Racial disparities in immediate breast reconstruction after mastectomy: impact of state and federal health policy changes. Ann Surg Oncol 20(2):399-406. doi:10.1245/s10434-012-2607-9

\section{Submit your manuscript to a SpringerOpen ${ }^{\circ}$ journal and benefit from:}

- Convenient online submission

- Rigorous peer review

- Immediate publication on acceptance

- Open access: articles freely available online

- High visibility within the field

- Retaining the copyright to your article

Submit your next manuscript at springeropen.com 